\title{
Home Mechanical Ventilation in Canada: A National Survey
}

\author{
Louise Rose RN PhD, Douglas A McKim MD FRCPC, Sherri L Katz MD FRCPC, \\ David Leasa MD FRCPC, Mika Nonoyama RRT PhD, Cheryl Pedersen MSc, \\ Roger S Goldstein MB BCh FRCPC, and Jeremy D Road MD FRCPC \\ on behalf of the CANuVENT Group
}

\begin{abstract}
BACKGROUND: No comprehensive Canadian national data describe the prevalence of and service provision for ventilator-assisted individuals living at home, data critical to health-care system planning for appropriate resourcing. Our objective was to generate national data profiling service providers, users, types of services, criteria for initiation and monitoring, ventilator servicing arrangements, education, and barriers to home transition. METHODS: Eligible providers delivering services to ventilator-assisted individuals (adult and pediatric) living at home were identified by our national provider inventory and referrals from other providers. The survey was administered via a web link from August 2012 to April 2013. RESULTS: The survey response rate was 152/171 $(89 \%)$. We identified 4,334 ventilator-assisted individuals: an estimated prevalence of 12.9/100,000 population, with $73 \%$ receiving noninvasive ventilation (NIV) and $18 \%$ receiving intermittent mandatory ventilation (9\% not reported). Services were delivered by 39 institutional providers and 113 community providers. We identified variation in initiation criteria for NIV, with polysomnography demonstrating nocturnal hypoventilation (57\%), daytime hypercapnia (38\%), and nocturnal hypercapnia (32\%) as the most common criteria. Various models of ventilator servicing were reported. Most providers $(64 \%)$ stated that caregiver competency was a prerequisite for home discharge; however, repeated competency assessment and retraining were offered by only $45 \%$. Important barriers to home transition were: insufficient funding for paid caregivers, equipment, and supplies; a shortage of paid caregivers; and negotiating public funding arrangements. CONCLUSIONS: Ventilatory support in the community appears well-established, with most individuals managed with NIV. Although caregiver competency is a prerequisite to discharge, ongoing assessment and retraining were infrequent. Funding and caregiver availability were important barriers to home transition. Key words: home ventilation; ventilator-assisted individuals; chronic respiratory failure; outcomes. [Respir Care 2015;60(5):695-704. @ 2015 Daedalus Enterprises]
\end{abstract}

\section{Introduction}

Ventilator-assisted individuals living at home are a small yet growing population with unique and variable care needs.

Dr Rose is affiliated with the Department of Critical Care and Research Institute, Sunnybrook Health Sciences Centre; the Lawrence S Bloomberg Faculty of Nursing, University of Toronto; the Provincial Centre of Weaning Excellence/Prolonged Ventilation Weaning Centre, Toronto East General Hospital; Mt Sinai Hospital; Li Ka Shing Knowledge Institute, St Michael's Hospital; and West Park Healthcare Centre, Toronto, Ontario, Canada. Dr McKim is affiliated with Respiratory Rehabilitation and the Sleep Centre, The Ottawa Hospital, and the Department of Medicine, University of Ottawa, Ottawa, Ontario, Canada. Dr Katz is affiliated with the Children's Hospital of Eastern Ontario (CHEO), the CHEO Research Institute, and the University of Ottawa, Ottawa, Ontario, Canada. Dr Leasa is affiliated with the London Health Sciences Centre and the Department
International reports estimate that their prevalence ranges from $6.6^{1}$ to $20.0^{2,3}$ per 100,000 adults and from $4.2^{4}$ to $6.7^{5}$ per 100,000 children under the age of $18 \mathrm{y}$. All international reports indicate that prevalence continues to rise due to advances in diagnostic and supportive technology,

\footnotetext{
of Medicine, University of Western Ontario, London, Ontario, Canada. Dr Nonoyama is affiliated with the University of Ontario Institute of Technology, Oshawa, Ontario, Canada. Ms Pedersen is affiliated with the Centre for Research in Inner City Health, Li Ka Shing Institute, St Michael's Hospital, Toronto, Ontario, Canada. Dr Goldstein is affiliated with the West Park Healthcare Centre and the Departments of Medicine and Physical Therapy, University of Toronto, Toronto, Ontario, Canada. Dr Road is affiliated with Vancouver General Hospital; the Provincial Respiratory Outreach Program, Vancouver Coastal Health; and the University of British Columbia, Vancouver, British Columbia, Canada.
} 
improved health-care delivery, and better understanding of the beneficial effects on quality of life $e^{6-8}$ and potential cost savings to health-care systems. ${ }^{9}$ Several single-center studies conducted in Canada reported a rising prevalence of ventilator-assisted children. ${ }^{10,11}$ Although a report from the Provincial Respiratory Outreach Program in British Columbia $^{12}$ indicated the prevalence to be $9.5 / 100,000$ adults in a single province, no comprehensive national data describe prevalence of such individuals.

There are 2 main categories of patients who receive home mechanical ventilation: 1) elective long-term mechanical ventilation resulting from conditions leading to progressive respiratory failure, such as neuromuscular disease, and 2) emergent long-term mechanical ventilation due to failure to wean from mechanical ventilation after an episode of acute respiratory failure. ${ }^{13}$ International reports of home mechanical ventilation indicate regional variation in the primary indication for ventilation. The largest survey of home mechanical ventilation conducted to date (the Eurovent survey) found that the relative proportion of ventilator-assisted individuals with neuromuscular and lung diseases varied substantially across the 16 countries surveyed. ${ }^{1}$ Similar variability was reported in a recent survey comparing prescribing patterns in Australia and New Zealand. ${ }^{14}$ Moreover, this survey reported lower rates of home mechanical ventilation for individuals with COPD compared with surveys from other countries. ${ }^{1,15,16}$ Practice variation in home mechanical ventilation prescription may be related to numerous factors, including perceived effectiveness in improving symptoms, quality of life, and mortality; population characteristics; and access to equipment. ${ }^{14}$

Due to the highly variable care needs of ventilatorassisted individuals living at home, as well as the risk of caregiver burnout, ${ }^{17,18}$ there is a need to ensure provision of appropriate health-care services, adequate funding for equipment and caregivers, a safe home environment, and client and caregiver education. ${ }^{19}$ Barriers that delay transition from the acute care setting to the home increase costs to the health-care system and result in unnecessary stress to ventilator-assisted individuals and their family members. Many of these barriers may be successfully ne-

The work was supported by a grant from the Partnerships for Health System Improvement Competition of the Canadian Institutes of Health Research.

The authors have disclosed no conflicts of interest.

Correspondence: Louise Rose RN PhD, Lawrence S Bloomberg Faculty of Nursing, University of Toronto, 155 College Street, Room 276, Toronto, Ontario M5T IP8, Canada. E-mail: louise.rose@utoronto.ca.

DOI: $10.4187 /$ respcare.03609

\section{QUICK LOOK}

\section{Current knowledge}

Ventilator-assisted individuals living at home are a small yet growing population with unique care needs. International reports estimate that their prevalence ranges from 6.6 to $20 / 100,000$ adults and from 4.2 to $6.7 / 100,000$ children. There is no comprehensive national database that describes the prevalence of ventilator-assisted individuals in Canada.

\section{What this paper contributes to our knowledge}

The estimated prevalence of ventilator-assisted individuals living at home in Canada demonstrates that this is a well-established approach to the long-term management of respiratory failure. Considerable variability in terms of many important care aspects, including when to initiate and how to monitor ventilatory support, provision of caregiver education, and ongoing competency assessment, suggests the need for knowledge translation of recent Canadian guidelines.

gotiated with a well-devised interprofessional transition plan. ${ }^{13}$

Our objective was therefore to generate national data profiling service providers, service users (adult and pediatric), types of services delivered, criteria for initiation and monitoring ventilation, ventilator types and servicing arrangements, education and follow-up, and barriers to home transition. Our CANuVENT Group has conducted similar surveys of long-term care facilities providing care to ventilator-assisted individuals ${ }^{20}$ and ICUs providing care to patients considered medically stable and ventilated for $>21 \mathrm{~d}^{21}$ Such data will enable planning and policy development for adult and pediatric health-care resources specific to ventilator-assisted individuals across the care continuum both nationally and provincially.

\section{Methods}

\section{Study Design and Sample}

Using an exploratory cross-sectional design, we conducted a survey that included service providers delivering care or services to ventilator-assisted individuals requiring daily noninvasive ventilation (NIV) or invasive mechanical ventilation via tracheostomy at home. We defined NIV as bi-level or biphasic mask or daytime mouthpiece ventilation (in the case of full-time support). Providers did not need to supply ventilators or equipment to be included. We excluded providers that delivered care only to individuals 
requiring CPAP or home oxygen and providers that had not delivered care or services in the preceding 12 months. Potentially eligible providers were identified during the development by our group of a national provider inventory and through referrals from other providers. The national provider inventory was compiled using existing provider databases held by members of our team, web searching, and screening questionnaires to institutions and providers to confirm types of services provided and identify additional providers. We screened all providers by telephone to confirm eligibility, seek agreement for questionnaire completion, and identify a survey champion who agreed to take responsibility for survey completion and return.

\section{Questionnaire Development}

Informed by domains and items of the Eurovent survey ${ }^{1}$ and the Canadian Thoracic Society home mechanical ventilation guidelines, ${ }^{13} 6$ team members representing medicine, nursing, and respiratory therapy iteratively refined domains, items, and response formats for the questionnaire. We programmed the web-based survey using Snap Professional software (Snap Surveys, London, United Kingdom) and then sent it to 8 experts in home mechanical ventilation (national and international) for feedback. We asked these experts to complete an assessment tool rating the survey's comprehensiveness, redundancy, clarity, and face validity and to pilot the survey to determine completion time and the number of health-care team members needed for the requested data. The final survey comprised 7 domains: provider characteristics, including services and education provided; user characteristics (age, ventilation type, primary disorder, duration of ventilation); criteria for initiation and monitoring ventilation effectiveness; equipment (ventilators and interfaces used, ventilator servicing arrangements and backup); training and education (audience, structure, topics, ongoing competency assessment); liaisons and transitions (referral, barriers to transition); and follow-up (structure, frequency, location).

\section{Questionnaire Administration}

Survey administration and data collection were managed by an independent survey unit (http://www.stmichaels hospital.com/crich/about/). This unit sent the online questionnaire via a secure web link to self-nominated champions (service directors or managers, physicians, registered nurses or respiratory therapists) from August 2012 to April 2013. Survey champions were directed to request data from other interprofessional team members to facilitate questionnaire completion. We sent weekly telephone and e-mail reminders for 6 weeks, with 2 last-chance reminders in April 2013.

\section{Ethical Considerations}

The research ethics boards of the University of Toronto and St Michael's Hospital approved the study. Participation was voluntary, and consent was implied by questionnaire return.

\section{Statistical Analyses}

We summarized continuous variables as mean \pm SD or median and interquartile range depending on data distribution, and we summarized categorical variables as frequencies and proportions. We compared services provided by institutional and community providers, as well as primary indications for invasive mechanical ventilation and NIV using a chi-square test or the Fisher exact tests depending on individual cell size. To facilitate an estimation of ventilator-assisted individual prevalence, Canadian and provincial population census numbers were obtained from the 2011 report of Statistics Canada. ${ }^{22}$ Due to missing responses, denominators varied. Analyses were conducted using SPSS 22 (IBM, Armonk, New York).

\section{Results}

We screened 283 providers, of which 112 were ineligible for the following reasons: 79/112 (70.5\%) did not provide service to ventilator-assisted individuals living at home, 23/112 (20.5\%) had not provided services within the last 12 months, and 10/112 (9\%) did not provide direct patient care. We received 152 surveys from all 171 eligible providers, resulting in a survey response rate of $89 \%$.

\section{Service Providers}

Of the 152 providers, 113 (74\%) were community providers with public $(43,38 \%)$, private $(20,18 \%)$, or combination funding models $(50,44 \%)$. The remaining 39 (26\%) were predominately publicly funded institutional providers that delivered services, including education and training, before hospital discharge to ventilator-assisted individuals transitioning to home (Table 1). Most community providers $(66,60 \%)$ delivered only local services. Of the institutional providers, most provided regional $(17,45 \%)$ or provincial $(15,40 \%)$ services. Approximately half the providers $(77,51 \%)$ delivered services to both adult and pediatric populations; $12(8 \%)$ delivered pediatric services only. The average duration of service provision to ventilator-assisted individuals since inception was $15.8 \pm 9.6 \mathrm{y}$. The types of services provided are shown in Table 2. Institutional providers were more frequently engaged in initiation and follow-up of ventilation, caregiver training, team assessments, case management, adolescent transition, and psychological counseling. 
Table 1. Characteristics of Service Providers

\begin{tabular}{lr}
\hline \hline \multicolumn{1}{c}{ Institution Type $(N=152)$} & $n(\%)$ \\
\hline Institutional providers & $39(26)$ \\
Acute care hospital out-patient clinic & $15(38)$ \\
Acute rehabilitation center with home & $9(23)$ \\
$\quad$ mechanical ventilation service & \\
Acute care hospital with home mechanical & $7(18)$ \\
$\quad$ ventilation service & \\
Non-hospital out-patient clinic & $4(10)$ \\
Chronic care/rehabilitation center with home & $3(8)$ \\
mechanical ventilation service & \\
Hospice & $1(3)$ \\
Community providers & $113(74)$ \\
Home respiratory care companies & $48(42)$ \\
Home-care agencies & $36(32)$ \\
Care-coordinating centers & $16(14)$ \\
Supportive housing & $8(7)$ \\
Community support services & $3(3)$ \\
Provincial home mechanical ventilation service & $2(2)$ \\
\hline
\end{tabular}

\section{Service Users}

We identified 4,334 ventilator-assisted individuals from 133 providers able to report client numbers; 2,423 (56\%) were identified by 31 institutional providers, and 1,911 (44\%) were identified by 102 community providers (Table 3). This provides an estimated prevalence of ventilator-assisted individuals living at home of 12.9/100,000 population, although prevalence varied across provinces. Of the 4,334 ventilator-assisted individuals, 3,181 (73\%) were receiving NIV, and $770(18 \%)$ were receiving invasive mechanical ventilation (383 [9\%] not reported). Institutional providers delivered services to more clients than those in the community (median 23 vs $5, P<.001$ ) despite 2 community providers of provincial service delivering services to $>1,400$ ventilator-assisted individuals. Data on age were provided for 1,998 clients: 425 (21\%) were $\leq 18$ y old, 1,077 (54\%) were adults between 18 and $65 \mathrm{y}$ of age (of whom 54 [3\%] were identified by pediatric providers awaiting transition to adult services), and 496 (25\%) were $>65$ y old. Data on primary diagnosis responsible for ventilation were provided for 1,715 adults (Fig. 1) and 311 children and adolescents (Fig. 2). Rates of ventilation initiation in the preceding 12 months were reported by 99 providers: 80 individuals were on invasive mechanical ventilation, 748 on part-time NIV, and 77 on full-time NIV $(24 \mathrm{~h} / \mathrm{d})$.

\section{Criteria for Initiation and Monitoring of NIV}

Fifty-nine providers indicated that they routinely initiated NIV. The most common locations for NIV initiation (reported as $\geq 50 \%$ of the time) were sleep laboratories
(37, 63\%), ICUs $(27,46 \%)$, and in-patient units $(21,36 \%)$. Considerable variation in initiation criteria was found. Those used most commonly ( $\geq 50 \%$ of the time) were polysomnography demonstrating nocturnal hypoventilation (30/53, 57\% of providers), daytime hypercapnia $(20 / 52,38 \%)$, and nocturnal hypercapnia $(16 / 50,32 \%)$. Conversely, $21 / 50(42 \%)$ providers stated that they never used nocturnal hypercapnia, 16/52 (31\%) never used daytime hypercapnia, and 6/53 (11\%) never used polysomnography to guide initiation. Tests of respiratory muscle strength were used least often: only $7(15 \%)$ providers used them $\geq 50 \%$ of the time, and $21(44 \%)$ never used them. Improvement of symptoms $(99 / 130,76 \%)$, subjective assessment by the patient or caregiver $(84 / 128,66 \%)$, ventilator download data $(67 / 125,54 \%)$, and overnight oximetry $(66 / 126,52 \%)$ were the parameters used by the majority of providers to monitor NIV effectiveness.

\section{Equipment}

Types of ventilators and interfaces are shown in Figure 3. Of the 152 providers, 129 reported data on frequency of ventilator servicing. Only $39(30 \%)$ indicated that ventilators were serviced routinely, with frequency ranging from 2 to 60 months. Other providers indicated that servicing frequency depended on the ventilator type $(30,23 \%)$ or hours of usage $(19,15 \%)$ or occurred only when requested by the user $(27,21 \%)$ or by a member of the health-care team $(6,5 \%)$. Eight $(6 \%)$ providers indicated that ventilators were not serviced. Various models of ventilator servicing arrangements were reported by 136 providers, such as use of external companies, including manufacturers $(49,36 \%)$; use of technicians associated with another organization, including provincial services such as the Ventilator Equipment Pool in Ontario or the Provincial Respiratory Outreach Program in British Columbia (46, 34\%); and technicians within their own institution $(20,22 \%)$. Two (1\%) providers indicated that health-care professionals serviced equipment, and 9 (7\%) were unaware of servicing arrangements. Of the 78 providers delivering services to clients requiring invasive mechanical ventilation and able to provide data, $53(68 \%)$ indicated that all clients had a backup ventilator, whereas $12(15 \%)$ indicated that none of their clients had a backup ventilator. Of the 82 providers delivering services to clients requiring NIV and able to provide data, only $12(15 \%)$ indicated that all clients had a backup device, and $41(50 \%)$ indicated that none of their clients had backup.

\section{Training and Education}

Training for health-care workers within the organization was offered by $87 / 143(61 \%)$ providers; $41 \%$ offered training to health-care workers external to their own organiza- 
Table 2. Services Provided

\begin{tabular}{|c|c|c|c|}
\hline Service & $\begin{array}{l}\text { Community Provider } \\
\quad(n=113), n(\%)\end{array}$ & $\begin{array}{l}\text { Institutional Provider } \\
\quad(n=39), n(\%)\end{array}$ & $P$ \\
\hline Tracheostomy care & $77(69)$ & $29(74)$ & .55 \\
\hline Home oximetry monitoring & $74(66)$ & $26(67)$ & $>.99$ \\
\hline Provision of disposable supplies & $62(55)$ & $18(46)$ & .18 \\
\hline Ventilator monitoring & $57(51)$ & $24(62)$ & .27 \\
\hline Equipment maintenance & $55(49)$ & $20(51)$ & $>.99$ \\
\hline Airway clearance strategies & $52(46)$ & $28(72)$ & $<.01$ \\
\hline Lung volume recruitment & $44(39)$ & $23(59)$ & .04 \\
\hline Caregiver training & $43(38)$ & $31(80)$ & $<.001$ \\
\hline Equipment for manually assisted cough & $41(37)$ & $25(64)$ & $<.01$ \\
\hline NIV initiation & $41(37)$ & $29(74)$ & $<.001$ \\
\hline 24-h hot line & $39(35)$ & $11(28)$ & .56 \\
\hline Case management & $35(31)$ & $20(51)$ & .03 \\
\hline Interprofessional team assessment & $31(28)$ & $26(67)$ & $<.001$ \\
\hline Mechanical in-exsufflation device/equipment & $27(24)$ & $20(51)$ & $<.01$ \\
\hline Provision of ventilators & $23(20)$ & $20(51)$ & .004 \\
\hline Ethics consultation & $16(14)$ & $20(51)$ & $<.001$ \\
\hline Financial resources & $15(13)$ & $10(26)$ & .09 \\
\hline Home mechanical ventilation out-patient clinic (NIV) & $12(11)$ & $28(72)$ & $<.001$ \\
\hline Ventilator weaning & $12(11)$ & $20(51)$ & $<.001$ \\
\hline Transition from pediatric-to-adult services & $12(11)$ & $24(62)$ & $<.001$ \\
\hline Psychological counseling for families & $9(8)$ & $9(23)$ & .02 \\
\hline Psychological counseling for clients & $8(7)$ & $9(23)$ & .02 \\
\hline $\begin{array}{l}\text { Home mechanical ventilation out-patient clinic } \\
\text { (invasive mechanical ventilation) }\end{array}$ & $7(6)$ & $27(69)$ & $<.001$ \\
\hline Telemedicine & $2(2)$ & $11(28)$ & $<.001$ \\
\hline
\end{tabular}

$\overline{\mathrm{NIV}}=$ noninvasive ventilation

Table 3. Client Characteristics

\begin{tabular}{|c|c|c|c|c|c|c|c|}
\hline & \multirow{2}{*}{ Sites, $n / N(\%) \dagger$} & \multirow{2}{*}{$\begin{array}{c}\text { Total } \\
\text { Ventilator-Assisted } \\
\text { Individuals, } n\end{array}$} & \multirow{2}{*}{ Prevalence } & \multicolumn{2}{|c|}{$\begin{array}{c}\text { Invasive mechanical } \\
\text { ventilation, } n\end{array}$} & \multicolumn{2}{|c|}{$\mathrm{NIV}, n$} \\
\hline & & & & Full-Time & Part-Time & Full-Time & Part-Time \\
\hline Canada* & $132 / 152(87)$ & 4,334 & 12.9 & 395 & 185 & 271 & 2,556 \\
\hline Ontario & 77/85 (91) & 1,986 & 15.5 & 137 & 63 & 104 & 1,114 \\
\hline British Columbia & $15 / 19(79)$ & 633 & 14.4 & 100 & 24 & 79 & 392 \\
\hline Quebec & $8 / 13(62)$ & 1,193 & 15.1 & 27 & 24 & 38 & 809 \\
\hline Alberta & $11 / 12(92)$ & 306 & 8.4 & 68 & 52 & 30 & 136 \\
\hline New Brunswick & $10 / 10(100)$ & 77 & 10.3 & 11 & 2 & 4 & 59 \\
\hline Saskatchewan & $7 / 8(88)$ & 61 & 5.9 & 17 & 5 & 0 & 34 \\
\hline Manitoba & $2 / 3(67)$ & 51 & 4.2 & 26 & 13 & 0 & 12 \\
\hline Newfoundland & $1 / 1(100)$ & 23 & 4.5 & 8 & 0 & 15 & 0 \\
\hline Nova Scotia & 1/1 (100) & 4 & 0.4 & 1 & 2 & 1 & 0 \\
\hline \multicolumn{8}{|c|}{$\begin{array}{l}\text { Numbers describing types of ventilation do not sum to total, as some providers were not able to break down service provision according to ventilation type. } \\
* \text { No ventilator-assisted individuals living at home were identified in Prince Edward Island, Yukon, Nunavut, and Northwest Territories. } \\
\dagger \text { Values indicate the number of sites that provided data on ventilator-assisted individual numbers }(N=\text { total number of sites). } \\
\S \text { Values indicated the prevalence in a population of } 100,00 \text { based on } 2011 \text { data from Statistics Canada (22). } \\
\text { NIV = noninvasive ventilation }\end{array}$} \\
\hline
\end{tabular}

tion. Education for patients and their family caregivers was delivered by 142/143 (99\%) providers reporting these data. The main topic areas covered are presented in
Table 4. Caregiver demonstration of competence before home discharge was identified as a prerequisite by $84 / 131$ (64\%) providers. Of these, $25(30 \%)$ indicated that com- 


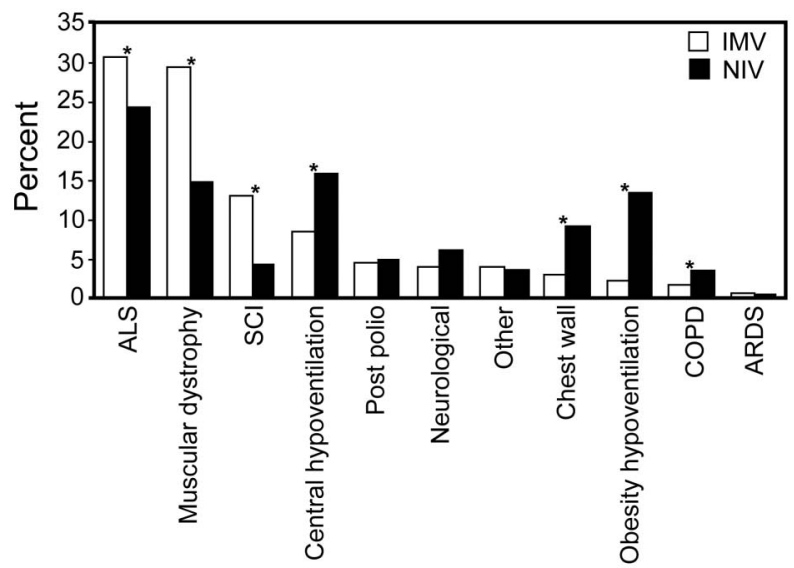

Fig. 1. Indications for ventilation in adults. ${ }^{*}$ Statistically significant $P$ value: amyotrophic lateral sclerosis (ALS), $P=.007$; muscular dystrophy, spinal cord injury (SCl), central hypoventilation, chest wall, and obesity hypoventilation, $P<.001$; COPD, $P=.04$. IMV = invasive mechanical ventilation; NIV = noninvasive ventilation; other = see text for full description.

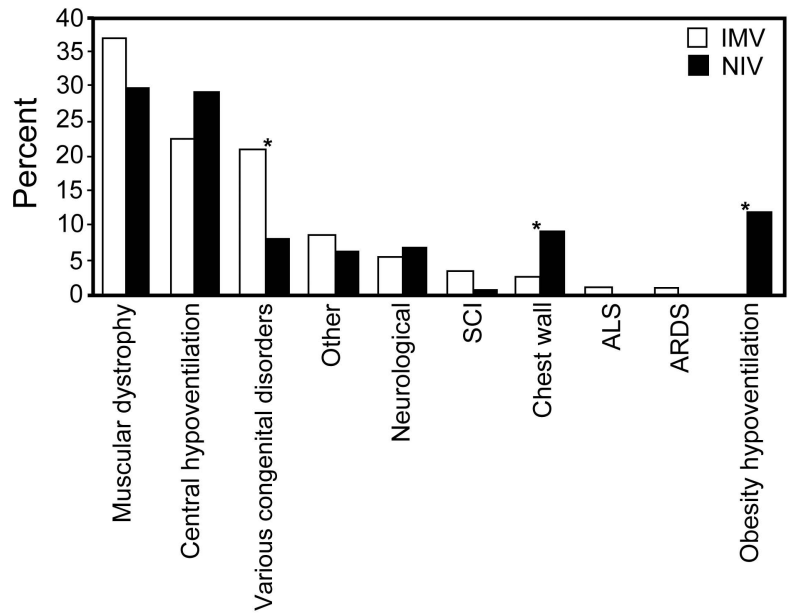

Fig. 2. Indications for ventilation in children and adolescents. * Statistically significant $P$ value: various congenital disorders, $P=.001$; chest wall, $P=.02$; obesity hypoventilation, $P<.001$. IMV = invasive mechanical ventilation; NIV = noninvasive ventilation; $\mathrm{SCl}=$ spinal cord injury; ALS = amyotrophic lateral sclerosis; other $=$ see text for full description.

petency assessment was performed by another provider, $24(29 \%)$ used return demonstration of skills, $8(10 \%)$ used in-hospital observation during which the family assumed full care, 7 (8\%) used formal competency or safety checklists, 6 (7\%) used supervision and evaluation in the home, and 3 (4\%) used general understanding. Repeated competency assessment and retraining of informal caregivers were offered by 60/133 (45\%) providers.

\section{Liaisons and Transition}

A variety of strategies were used to facilitate access and awareness to home mechanical ventilation service pro- viders. Most received referrals from specialists, general practitioners, or community support coordination centers, although some received referrals from other health professionals, such as social workers and rehabilitation specialists. Self-referral or friend/family referral also occurred.

The top 3 barriers experienced $\geq 50 \%$ of the time during home transition for individuals receiving invasive mechanical ventilation were insufficient public funding for paid caregivers (including nurses and personal support workers), a shortage of paid caregivers, and negotiating public funding arrangements. The top 3 barriers experienced $\geq 50 \%$ of the time during home transition for individuals receiving NIV were insufficient funding (either public or private) for equipment and supplies, insufficient public funding for paid caregivers, and again negotiating public funding arrangements (Fig. 4).

\section{Follow-Up}

Ongoing follow-up was provided by $106(75 \%)$ of the 142 providers reporting these data: $56(53 \%)$ indicated that this occurred only at home, $27(25 \%)$ indicated that this occurred both at home and in out-patient clinics, 19 (18\%) indicated that this occurred only in out-patient clinics, and $4(4 \%)$ indicated that this occurred at an alternate venue. Follow-up in the home was conducted via telemedicine and in person by one provider. Frequency of clinic follow-up ranged from 1 month to annually, with the most common response being as indicated by the ventilatorassisted individual's condition $(16,35 \%)$. Frequency of home follow-up was also most commonly based on the ventilator-assisted individual's condition (44, 53\%). Procedures or tests carried out during follow-up visits are listed in Table 5. Primary responsibility for tracheostomy changes varied across providers, including respiratory therapists $(53 / 118,45 \%)$, physicians $(32 / 114,28 \%)$, informal caregivers $(28 / 115,24 \%)$, registered nurses $(23 / 112,21 \%)$, paid caregivers $(20 / 115,17 \%)$, and registered practical nurses $(8 / 104,8 \%)$.

\section{Discussion}

This study provided a comprehensive description of service provision for ventilator-assisted individuals living at home, with results that are highly generalizable within the Canadian context, considering the $89 \%$ response rate. Key findings include: variation in ventilator-assisted individual prevalence, number of providers across provinces, and number of ventilator-assisted individuals to whom providers delivered services; lack of standardization in the criteria used for initiation and monitoring of NIV; only moderate availability of airway clearance strategies, particularly from community providers; variability in ventilator servicing arrangements and provision of backup 


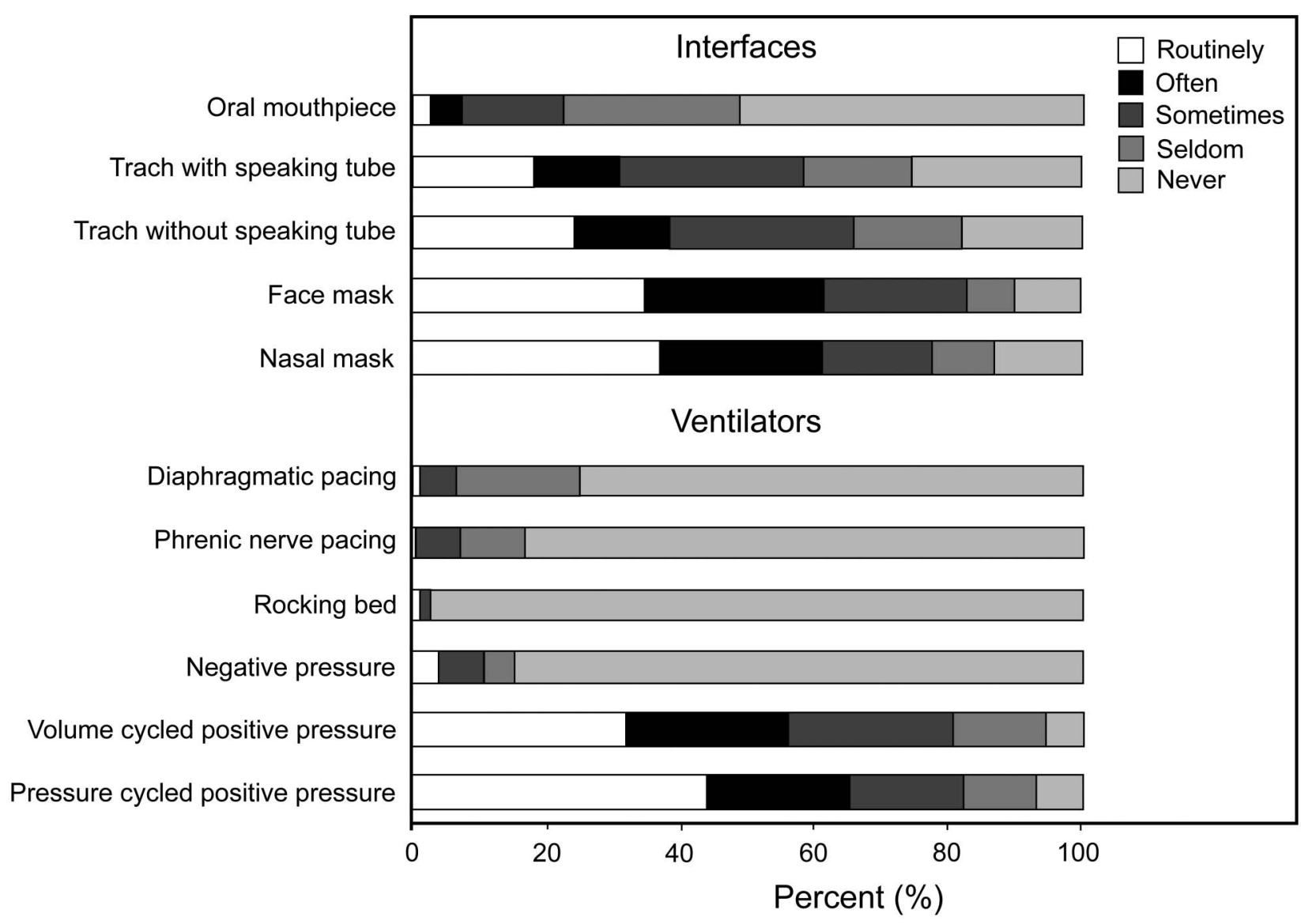

Fig. 3. Interfaces and ventilators.

Table 4. Main Topic Areas Covered During Client, Family Caregiver, and Health Worker Training

\begin{tabular}{|c|c|c|}
\hline Topic & $\begin{array}{l}\text { Client and Family } \\
(N=142), n(\%)\end{array}$ & $\begin{array}{l}\text { Health Worker } \\
(N=58), n(\%)\end{array}$ \\
\hline Equipment use and maintenance & $125(88)$ & $56(97)$ \\
\hline Overview of NIV & NA & $49(85)$ \\
\hline Suctioning & $119(84)$ & $44(76)$ \\
\hline Overview of invasive ventilation & NA & $43(74)$ \\
\hline Tracheostomy care & $99(70)$ & $38(66)$ \\
\hline $\begin{array}{l}\text { Secretion clearance techniques, such as } \\
\text { manually and mechanically assisted cough }\end{array}$ & $92(65)$ & $33(57)$ \\
\hline Management of acute respiratory deterioration & NA & $31(53)$ \\
\hline Anatomy and physiology & NA & $27(47)$ \\
\hline Lung volume recruitment & $60(42)$ & $26(45)$ \\
\hline Disaster planning & $57(40)$ & $25(43)$ \\
\hline Self-advocacy & $57(40)$ & NA \\
\hline Energy conservation & $49(35)$ & NA \\
\hline Other & $5(4)$ & 0 \\
\hline
\end{tabular}

ventilators; inconsistencies in family caregiver training, competency assessment, and ongoing follow-up; and inadequacy of current funding models.
Provincial variation in numbers and size of service providers reflects differences in models of care delivery and suggests the need for better coordination of services in 


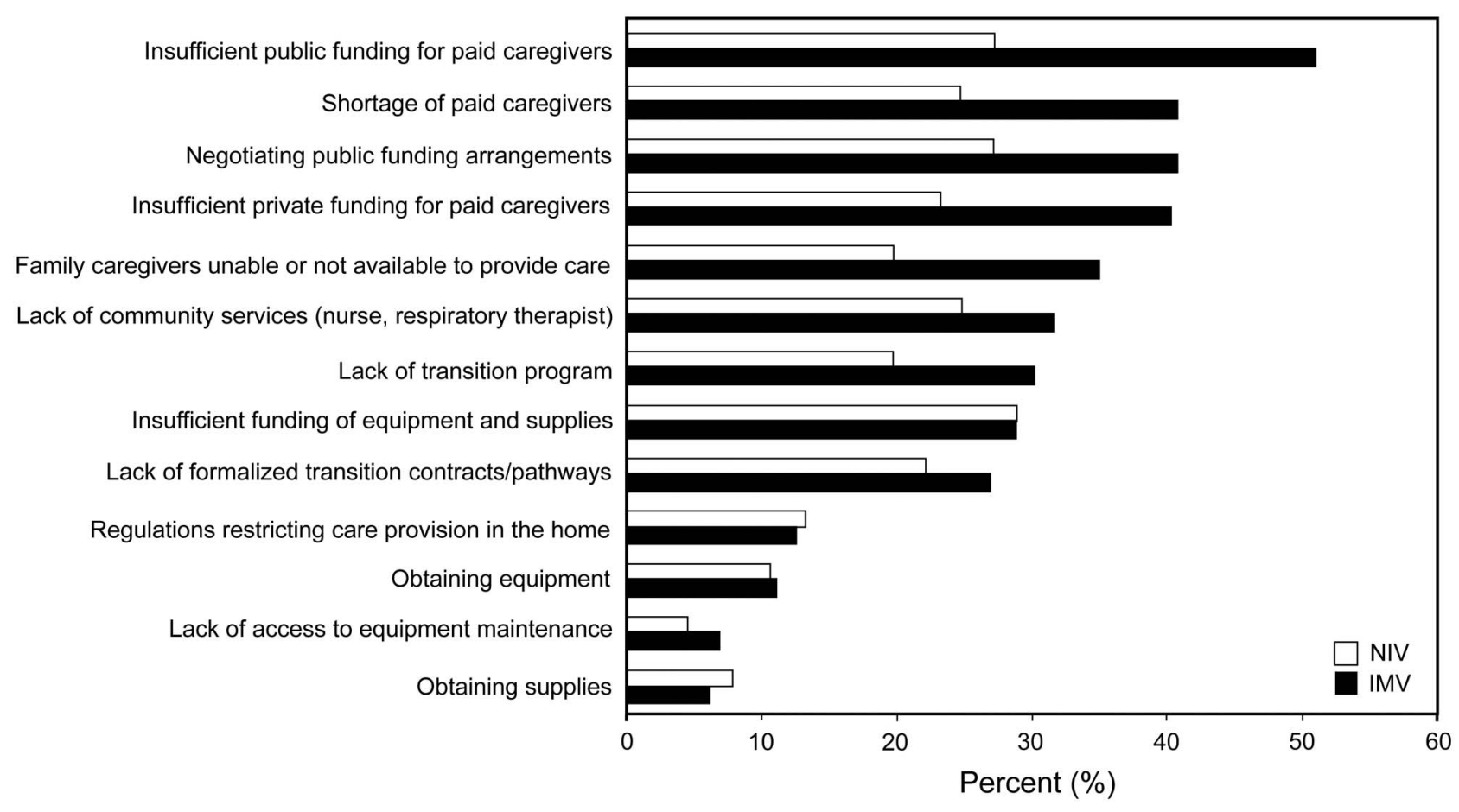

Fig. 4. Perceived barriers to home transition. IMV = invasive mechanical ventilation; NIV = noninvasive ventilation.

Table 5. Follow-Up Procedures and Tests

\begin{tabular}{lc}
\hline \hline \multicolumn{1}{c}{ Follow-up procedures and tests } & $n(\%)$ \\
\hline Ventilator compliance/adherence assessment & $74(71)$ \\
Assessment of self-management techniques & $74(71)$ \\
Ventilator performance check & $65(63)$ \\
Tracheostomy care & $51(19)$ \\
Overnight oximetry & $50(48)$ \\
Arterial or capillary blood gas & $20(19)$ \\
Spirometry & $19(18)$ \\
Other & $16(15)$ \\
Polysomnography & $8(8)$ \\
Daytime oximetry & $5(5)$ \\
Overnight transcutaneous $\mathrm{CO}_{2}$ monitoring & $3(3)$ \\
\hline$N=105$. Other comprised respiratory physical assessment; other equipment checks; mask fit; \\
peak cough flows; ventilator circuit change; general assessment of health, care needs, and \\
family situation; assessment of family caregiver skills; and end-tidal $\mathrm{CO}_{2}$. \\
\hline
\end{tabular}

some regions. For example, Ontario appears to have substantial provincial resources for ventilator-assisted individuals; however, the system appears fragmented, with many community providers delivering services to small numbers of users despite a centralized ventilator equipment pool funded by the Ministry of Health and LongTerm Care. ${ }^{23}$ Other provinces with comparatively large populations, such as British Columbia and Quebec, have very few providers despite large numbers of ventilatorassisted individuals. This is a result of centralization of equipment provision and services with organizations such as the Provincial Respiratory Outreach Program in British Columbia $^{12}$ and the National Program for Home Ventilatory Assistance in Quebec (http://www.nphva.ca/, Accessed November 24, 2014). Note that despite the title of this organization suggesting a Canada-wide program, this comprehensive service is limited to the province of Quebec.

We detected substantial variation in criteria used for initiation and monitoring NIV, reasons for which are unclear. Current Canadian Thoracic Society evidence-based recommendations ${ }^{13}$ indicate that criteria for NIV initiation differ depending on primary diagnosis. For example, orthopnea and daytime hypercapnia are used for patients with amyotrophic lateral sclerosis, nocturnal hypercapnia for patients with obstructive and central hypoventilation syndrome, daytime hypercapnia or symptomatic nocturnal hypoventilation for patients with Duchenne and other muscular dystrophies, and polysomnography for patients with central and obesity hypoventilation syndromes. ${ }^{13}$ However, for the most part, providers initiated NIV for individuals with a range of diagnoses; therefore, variability is likely due to availability of resources such as access to polysomnography and clinician preference. Similarly, airway clearance techniques were not universally available despite evidence-based recommendations for their use in ventilator-assisted individuals with peak cough flows of $<270 \mathrm{~L} / \mathrm{min}$ and as a complement to deep suctioning for ventilator-assisted individuals with tracheostomies in the absence of contraindications. ${ }^{13}$ In addition, the prevalence of NIV use in amyotrophic lateral sclerosis was less com- 
pared with invasive ventilation, although this finding needs to be interpreted with caution due to the inability of many providers to report on ventilator-assisted individual diagnosis. These findings suggest the need for active knowledge translation of the Canadian Thoracic Society home mechanical ventilation guidelines to reduce variation and improve outcomes.

Variability in equipment maintenance, provision of back-up ventilators, and expectations regarding family caregiver competencies raises potential safety concerns. Similar variability (both inter-country and intra-country) was identified in the Eurovent survey. ${ }^{24}$ Issues relating to ventilator equipment failure are not infrequent. In the United Kingdom, Chatwin and colleagues ${ }^{25}$ reported on 1,211 ventilator-assisted individuals receiving NIV over a 6-month time frame and found an $8 \%$ failure rate per NIV device manufacturer, with higher failure rates in highly ventilator-dependent individuals and older devices. An earlier study of mostly tracheostomized ventilatorassisted individuals reported 189 equipment-associated issues in 150 users over $1 \mathrm{y}$ and found that $43 \%$ were due to improper use or care of equipment by caregivers. ${ }^{26}$ This finding highlights the need for routine servicing and ongoing education regarding technology for family caregivers.

Inadequacy of public and private funding for caregivers and equipment, difficulties negotiating public funding arrangements, and lack of caregivers were frequently experienced barriers. Home-care services are not included under the Canada Health Act, but are funded primarily though provincial governments, ${ }^{27}$ depending on individual need with a predetermined maximum number of hours. ${ }^{28}$ In Ontario, for example, Regulation 386/99 under the Home Care and Community Services Act defines the maximum hours provided by community care access centers for nursing (registered nurses and registered practical nurses) and personal support hours as 206 and $120 \mathrm{~h}$, respectively, for a 30-d period. ${ }^{29}$ Under the same act, respiratory therapy is considered an additional professional service. However, since their inclusion in 2009, respiratory therapy services have not been utilized formally or systematically across all community care access centers in Ontario. Our study found that insufficient public funding for paid caregivers was the main barrier to home transition, suggesting that these provincially determined maximum hours are insufficient to meet the needs of ventilator-assisted individuals living at home. Conversely, difficulty accessing equipment and disposables was infrequent, which likely reflects efficiencies enabled by centralized provincial programs, such as the Ventilator Equipment Pool, Provincial Respiratory Outreach Program, and National Program for Home Ventilatory Assistance.

\section{Limitations}

Ventilator-assisted individual prevalence was likely underestimated in some provinces due to the inability of participants to provide data on ventilator-assisted individual numbers, the potential for failing to identify all eligible providers, and the $11 \%$ of eligible providers that did not return the survey. Conversely, we may have double-counted some ventilator-assisted individuals who receive services from a community and institutional provider. Other limitations are respondent and social desirability bias related to self-report surveys and the characterization of primary diagnoses resulting in ventilation that was not validated by the treating physician.

\section{Conclusions}

The estimated prevalence of ventilator-assisted individuals living at home in Canada indicates that ventilatory support in the community is a well-established approach to the longer term management of respiratory failure. Considerable variability in terms of many important care aspects, including when to initiate and how to monitor ventilatory support, provision of caregiver education, and ongoing competency assessment, suggests the need for knowledge translation of recent Canadian Thoracic Society guidelines as well as a standardized care strategy offering the ideal working model of best practice for ventilator-assisted individuals. This would enable benchmarking of service providers while recognizing the need for flexibility due to geographic challenges, policy variation, and available resources. This study provides important data required to understand the needs of ventilator-assisted individuals and their family members so that appropriate public resources are provided to maintain quality of life at home.

\section{CANuVENT Group}

Reshma Amin MD FRCPC, The Hospital for Sick Children, Toronto, Ontario, Canada.

Monica Avendano MD FRCP, Roger Goldstein MB BCh FRCPC, West Park Healthcare Centre, Toronto, Ontario, Canada.

Sandra Dial MD MSc, Montreal Chest Institute, Montreal, Quebec, Canada.

Eddy Fan MD MPH PhD, Mount Sinai Hospital, Toronto, Ontario, Canada.

Ian Fraser MD FRCPC, Toronto East General Hospital, Toronto, Ontario, Canada.

Robert Fowler MD MDCM MSc and Gordon Rubenfeld MD MSc, Sunnybrook Health Sciences Centre, Toronto, Ontario, Canada.

Sherri Katz MD FRCPC, Children's Hospital of Eastern Ontario, Ottawa, Ontario, Canada. 
Judy King PT PhD, University of Ottawa, Ottawa, Ontario, Canada.

David Leasa MD FRCPC and Cathy Mawdsley, London Health Sciences Centre, London, Ontario, Canada.

Douglas McKim MD FRCPC, Ottawa Hospital, Ottawa, Ontario, Canada.

Mika Nonoyama RRT PhD, University of Ontario Institute of Technology, Oshawa, Ontario, Canada.

Jeremy Road MD FRCPC, Provincial Respiratory Outreach Program, Vancouver Coastal Health, Vancouver, British Columbia, Canada.

Louise Rose RN MN PhD, University of Toronto, Toronto, Ontario, Canada.

\section{REFERENCES}

1. Lloyd-Owen SJ, Donaldson GC, Ambrosino N, Escarabill J, Farre R, Fauroux B, et al. Patterns of home mechanical ventilation use in Europe: results from the Eurovent survey. Eur Respir J 2005;25(6): 1025-1031.

2. Tollefsen E, Gulsvik A, Bakke P, Fondenes O. [Prevalence of home ventilation therapy in Norway]. Tidsskr Nor Laegeforen 2009; 129(20):2094-2097. Article in Norwegian.

3. Laub M, Berg S, Midgren B. Home mechanical ventilation in Sweden-inequalities within a homogenous health care system. Respir Med 2004;98(1):38-42.

4. Racca F, Berta G, Sequi M, Bignamini E, Capello E, Cutrera R, et al. Long-term home ventilation of children in Italy: a national survey. Pediatr Pulmonol 2011;46(9):566-572.

5. Goodwin S, Smith H, Langton Hewer S, Fleming P, Henderson AJ, Hilliard T, Fraser J. Increasing prevalence of domiciliary ventilation: changes in service demand and provision in the South West of the UK. Eur J Pediatr 2011;170(9):1187-1192.

6. Noyes J. Comparison of ventilator-dependent child reports of healthrelated quality of life with parent reports and normative populations. J Adv Nurs 2007;58(1):1-10.

7. Windisch W. Quality of life in home mechanical ventilation study group: impact of home mechanical ventilation on health-related quality of life. Eur Respir J 2008;32(5):1328-1336.

8. Markström A, Sundell K, Lysdahl M, Andersson G, Schedin U, Klang B. Quality-of-life evaluation of patients with neuromuscular and skeletal diseases treated with noninvasive and invasive home mechanical ventilation. Chest 2002;122(5):1695-1700.

9. Sevick MA, Kamlet MS, Hoffman LA, Rawson I. Economic cost of home-based care for ventilator-assisted individuals: a preliminary report. Chest 1996;109(6):1597-1606.

10. McDougall CM, Adderley RJ, Wensley DF, Seear MD. Long-term ventilation in children: longitudinal trends and outcomes. Arch Dis Child 2013;98(9):660-665.

11. Amin R, Sayal P, Syed F, Chaves A, Moraes TJ, MacLusky I. Pediatric long-term home mechanical ventilation: Twenty years of follow-up from one Canadian center. Pediatr Pulmonol 2014;49(8): 816-824.

12. Provincial Respiratory Outreach Program. http://www.bcits.org/ proplink.htm. Accessed June 23, 2014.
13. McKim DA, Road J, Avendano M, Abdool S, Cote F, Duguid N, et al. Home mechanical ventilation: a Canadian Thoracic Society clinical practice guideline. Can Respir J 2011;18(4):197-215.

14. Garner DJ, Berlowitz DJ, Douglas J, Harkness N, Howard M, McArdle N, et al. Home mechanical ventilation in Australia and New Zealand. Eur Respir J 2013;41(1):39-45.

15. Mandal S, Suh E, Davies M, Smith I, Maher TM, Elliott MW, et al. Provision of home mechanical ventilation and sleep services for England survey. Thorax 2013;68(9):880-881.

16. Chu CM, Yu WC, Tam CM, Lam CW, Hui DS, Lai CK, et al. Home mechanical ventilation in Hong Kong. Eur Respir J 2004; 23(1):136-141.

17. Evans R, Catapano MA, Brooks D, Goldstein RS, Avendano M. Family caregiver perspectives on caring for ventilator-assisted individuals at home. Can Respir J 2012;19(6):373-379.

18. Carnevale FA, Alexander E, Davis M, Rennick J, Troini R. Daily living with distress and enrichment: the moral experience of families with ventilator-assisted children at home. Pediatrics 2006;117(1): e48-e60.

19. Brooks D, Gibson B, DeMatteo D. Perspectives of personal support workers and ventilator-users on training needs. Patient Educ Couns 2008;71(2):244-250.

20. Rose L, Leasa D, McKim D, Nonoyama M, Avendano M, Goldstein R, CANuVENT Group. Provision of institutional care for long-term mechanical ventilation in Canada: a national survey. Can Resp J 2014 [Epub ahead of print] pii: 16372.

21. Rose L, Fowler RA, Fan E, Fraser I, Leasa D, Mawdsley C, et al. Prolonged mechanical ventilation in Canadian intensive care units: a national survey. J Crit Care 2015;30(1):25-31.

22. Statistics Canada. Population and dwelling counts, for Canada, provinces and territories, 2011 and 2006 censuses. http://www12. statcan.gc.ca/census-recensement/2011/dp-pd/hlt-fst/pd-pl/TableTableau.cfm?LANG $=$ Eng $\& \mathrm{~T}=101 \& \mathrm{~S}=50 \& \mathrm{O}=\mathrm{A}$. Accessed May 8, 2014.

23. Ventilator Equipment Pool. Ontario's ventilator equipment pool. http://ontvep.ca/. Accessed June 23, 2014.

24. Farre R, Lloyd-Owen SJ, Ambrosino N, Donaldson G, Escarrabill J, Fauroux B, et al. Quality control of equipment in home mechanical ventilation: a European survey. Eur Respir J 2005;26(1): 86-94.

25. Chatwin M, Heather S, Hanak A, Polkey MI, Simonds AK. Analysis of home support and ventilator malfunction in 1,211 ventilatordependent patients. Eur Respir J 2010;35(2):310-316.

26. Srinivasan S, Doty SM, White TR, Segura VH, Jansen MT, Davidson Ward SL, Keens TG. Frequency, causes, and outcome of home ventilator failure. Chest 1998;114(5):1363-1367.

27. Health Canada. Home and community care. http://www.hc-sc.gc.ca/ hcs-sss/home-domicile/commun/index-eng.php. Accessed June 25, 2014.

28. Hermus G, Stonebridge C, Thériault L, Bounajm F. Home and community care in Canada: an economic footprint. The Conference Board of Canada. http://www.conferenceboard.ca/cashc/research/2012/ homecommunitycare.aspx. Accessed November 24, 2014.

29. ServiceOntario. Home Care and Community Services Act, 1994; Ontario Regulation 386/99; provision of community services. http:// www.e-laws.gov.on.ca/html/regs/english/elaws_regs_990386_e.htm. 2014. Accessed June 25, 2014. 